\title{
Approaches to diabetes: empowerment, control or both?
}

At its core, diabetes represents a failure of metabolic control. It creeps up on people, acutely in the case of Type 1 diabetes, and more insidiously in Type 2. It undermines autonomy and patients often feel disempowered. Some unseen internal mechanism no longer adequately regulates their glycaemic control, and longer term complications threaten to cause disability. Uncertainty lurks, with hypoglycaemia a risk from insulin or sulphonylureas, and cardiovascular events more common. Most medical approaches emphasise control, with drugs playing a critical role in augmenting glucose regulation or replacing insulin. Control is also important in lowering blood pressure and lipids so as to reduce the risk of cardiovascular events. However, these externally prescribed treatment regimens can further undermine autonomy and reinforce a sense of disempowerment.

In response to this, much rhetoric emphasises the role that empowered patients can play in managing their own diabetes. This empowerment approach, developed by Anderson and Funnell (2005), has been widely influential, underpinning structural education programmes and the UK National Service Framework (Department of Health, 2001). Evidence for its effectiveness is, however, hard to pin down because empowerment is a process, whereby people take control of their situation, rather than something that is done to them with an easily measurable intervention.

Both types of diabetes remain a challenge for primary health care around the world. Too often, the ideal scenario of empowered patients getting control of their condition with meaningful behavioural efforts and effective medication, supported in this by proactive health services, seems a distant hope. Three reports in this issue of the journal highlight the way that this goal can seem unachievable, leading to disillusionment and sometimes antagonism between doctors and patients.

In Belfast, most of the recently diagnosed patients who took part in a study on diet and physical activity found the changes they were

(C) Cambridge University Press 2013 being asked to make too daunting, even though they had received two half-day education sessions (Booth et al., 2012). The research identified few things that facilitated behaviour change, although positive feedback from feeling better and support from family members and health professionals were valued. In Oman, health professionals reported that workload pressures and the nurse role being underdeveloped were barriers to diabetes care. Worryingly, they also blamed their patients for not following advice on diet or medication (Noor Abdulhadi et al., 2012). Although the findings of the study conducted in Brussels were more nuanced, there was still a sense that health professionals were not adequately meeting patients' needs for information on diet. Initially, patients received some dietary advice from their general practitioners, but when they tried to apply it, they realised they needed more detail and to know where to find out more. The authors concluded that there was a need for public health strategies to help patients become better-informed and more proactive in their self-management (Meyfroidt et al., 2012).

Two audits describe a contrasting approach, emphasising the aim to control metabolic variables across the population. In Sweden, a National Diabetes Register has been established and primary health care centres record individual patient data online (Hallgren Elfgren et al., 2012). The aggregate data on $\mathrm{HbA} 1 \mathrm{c}$, blood pressure, lipids and albuminuria are then used as a 'tool for quality evaluation', although there is little detail on specific changes that have been informed by information from the register. A different approach was adopted in Norfolk, UK, where community pharmacists reviewed the records of patients registered with nine general practices (Twigg et al., 2012). This audit was able to look in more detail at whether the practices followed national guidance on monitoring and prescribing for Type 2 diabetes. Findings such as the observation that $38.6 \%$ of those who had total cholesterol 
values above $4.0 \mathrm{mmol} / \mathrm{L}$ were not prescribed lipidlowering medication reinforce the role that audits like this can play in tightening control over metabolic risk factors. However, whether this particular audit was used in this way is unclear, as no followup data is presented and it is unclear to what extent the general practices acted on the recommendations of the pharmacists.

Both of these audits were conducted at a distance from the consulting room, whereas the UK Quality and Outcomes Framework (QOF) has increasingly shaped the way that individual diabetes care is delivered in the United Kingdom (Campbell et al., 2009). Backed by significant financial resources, this pay-for-performance scheme emphasises control of risk factors and complications. General practitioners and practice nurses increasingly use templates to enter information, and on-screen alerts prompt action when individual patients' blood pressure, lipids or HbA1c do not meet the audit standard. This audit standard may not necessarily represent the goal that individual patients and their professional advisers may agree, and it is not a substitute for tailoring treatment to individual risk, but it does serve as a prompt to action in a condition where it is all too easy to accept mediocre results in the short term, despite the longer term risks that may arise.

Various approaches have been taken to enlist patients in controlling risk factors and the evaluation of a self-management package for chronic kidney disease is an example of this (Thomas and Bryar, 2013). Although methodological factors limit the generalisability of this work, the idea that patients should be more involved in managing this 'hidden' risk than just being asked to provide an annual early morning urine specimen deserves further research.

For many, it is self-evident that understanding a condition is a prerequisite to managing it well, and in the United Kingdom, the National Institute for Health and Care Excellence (NICE) recommends that structured education should be offered to patients and their carers at the time of diagnosis (NICE, 2009). Although there are concerns about the availability of education programmes in some areas of the country, the QOF standards have now been amended to include structured education for people who are newly diagnosed (NHS Employers, 2013). This change marks a fundamental shift from the previous emphasis on checking and controlling clinical risk factors and, instead, reinforces the importance of empowerment approaches in diabetes care.

Taken together, the reports published in this issue of the journal highlight the challenges that health professionals face in trying to adopt empowerment approaches, while at the same time focusing on controlling metabolic risks. These discussions get played out in individual consultations; however, as Wagner's Chronic Care Model emphasises, better management of chronic conditions requires change at a number of levels (Bodenheimer et al., 2002). The Chronic Care Model (CCM) predicts that improvement in its six interrelated components - self-management support, clinical information systems, delivery service redesign (which includes reviewing the training and roles of primary care team members), decision support, health care organisation and community resources - can produce system reform in which informed, activated patients interact with prepared, proactive practice teams. This provides a framework that has been widely welcomed, but is still not applied as often as it might be in individual service settings. If primary care around the world is to link the strategies of empowerment and control effectively, basing more of our work on the CCM would be a good place to start.

\section{Jonathan Graffy \\ Department of Public Health and Primary Care Universtiy of Cambridge, Cambridge Cambridgeshire, UK}

\section{References}

Anderson, R.M. and Funnell, M.M. 2005: Patient empowerment: reflections on the challenge of fostering the adoption of a new paradigm. Patient Education and Counseling 57, 153-57.

Bodenheimer, T., Wagner, E.H. and Grumbach, K. 2002: Improving primary care for patients with chronic illness. JAMA 288, 1775-79. Retrieved 16 April 2013 from http:// jama.ama-assn.org/cgi/content/abstract/288/14/1775

Booth, A.O., Lowis, C., Dean, M., Hunter, S.J. and McKinley, M.C. 2012: Diet and physical activity in the self-management of type 2 diabetes: barriers and facilitators identified by patients and health professionals. Primary Health Care Research \& Development, FirstView, 1-14. Retrieved from http://dx.doi.org/10.1017/S1463423612000412 
Campbell, S.M., Reeves, D., Kontopantelis, E., Sibbald, B. and Roland, M. 2009: Effects of pay for performance on the quality of primary care in England. The New England Journal of Medicine 361, 368-78. Retrieved from http:// content.nejm.org/cgi/content/abstract/361/4/368

Department of Health. 2001: National Service Framework for Diabetes: Standards. London: Department of Health.

Hallgren Elfgren, I.M., Grodzinsky, E. and Törnvall, E. 2012: Swedish diabetes register, a tool for quality development in primary health care. Primary Health Care Research \& Development, FirstView, 1-8. Retrieved from http:// dx.doi.org/10.1017/S1463423612000515

Meyfroidt, S., Aeyels, D., Van Audenhove, C., Verlinde, C., Peers, J., Panella, M. and Vanhaecht, K. 2012: How do patients with uncontrolled diabetes in the Brussels-Capital Region seek and use information sources for their diet? Primary Health Care Research \& Development, FirstView, 1-11. Retrieved from http://dx.doi.org/10.1017/S1463423612000205

National Institute for Health and Clinical Excellence (NICE). 2009: Type 2 diabetes: newer agents for blood glucose control in type 2 diabetes. London: NICE. Retrieved 16 April 2013 from http://www.nice.org.uk/nicemedia/live/ 12165/44318/44318.pdf
NHS Employers. 2013: Quality and Outcomes Framework: Guidance for GMS contract 2013/14. London: NHS Employers. Retrieved 16 April 2013 from http:// www.nhsemployers.org/Aboutus/Publications/Documents/ qof-2013-14.pdf

Noor Abdulhadi, N.M., Al-Shafaee, M.A., Wahlström, R. and Hjelm, K. 2012: Doctors' and nurses' views on patient care for type 2 diabetes: an interview study in primary health care in Oman. Primary Health Care Research \& Development, FirstView, 1-12. Retrieved from http:// dx.doi.org/10.1017/S146342361200062X

Thomas, N. and Bryar, R. 2013: An evaluation of a selfmanagement package for people with diabetes at risk of chronic kidney disease. Primary Health Care Research \& Development, FirstView, 1-11. Retrieved from http:// dx.doi.org/10.1017/S1463423612000588

Twigg, M.J., Desborough, J.A., Bhattacharya, D. and Wright, D.J. 2012: An audit of prescribing for type 2 diabetes in primary care: optimising the role of the community pharmacist in the primary healthcare team. Primary Health Care Research \& Development, FirstView, 1-5. Retrieved from http://dx.doi.org/10.1017/ S1463423612000345 